\section{Diagnosis, Management and Treatment of Septic Shock from Early Diagnosis to Infection Focus Control}

\section{Abstract}

Sepsis is a syndrome characterized by clinical signs and symptoms due to infection, with a high rate of mortality, especially if not recognized and treated promptly. In the last years, several definitions were explained about this syndrome. The aim of this review is to give a common and practical definition of septic shock, and to focus on diagnosis, early resuscitation and infection focus control.

Keywords: Sepsis; Septic shock; Antibiotic therapy; ARDS; Hypoperfusion; Emergency; Intensive Cardiac Unit

Received: February 06, 2018; Accepted: February 24, 2018; Published: February 26, 2018

\section{Introduction}

Sepsis is a syndrome characterized by clinical signs and symptoms due to infection, with a high rate of mortality, especially if not recognized and treated promptly. In the last years, several definitions were explained about this syndrome. The aim of this review is to give a common and practical definition of septic shock, and to focus on diagnosis, early resuscitation and infection focus control.

\section{Diagnosis}

The most important causes of sepsis are pneumonias, followed by intra-abdominal and urinary tract infections [1]. Actually, the high use of endovascular prosthesis and devices represent an important risk factor of infection and its complications. Bacteria are the most common cause of sepsis, both Gram-positive and Gram-negative. Staphylococcus aureus and Streptococcus pneumoniae are the most common Gram-positive isolates, while Escherichia Coli, Klebsiella spp., and Pseudomonas aeruginosa are the most represented among Gram-negative isolates [2].

There is an increasing role of methicillin- resistant Staphylococcus aureus (MRSA), not only in hospitalized patients, but also in community acquired infections [3]. Until 2016, sepsis was defined as a "Systemic inflammatory response syndrome (SIRS) with a documented infection" while severe sepsis was defined as "A systemic inflammatory response syndrome with a documented infection, related to organ failure, hypotension or reduced tissue function".

\section{Biagio Liccardo, Tiziana Formisano, Antonello D'Andrea*, Mario Giordano, Francesca Martone, Vincenzo Avitabile, Roberta Bottino, and Paolo Golino}

\author{
Department of Cardiology, Monaldi \\ Hospital-AORN Ospedali dei Colli, Luigi \\ Vanvitelli University, Naples, Italy
}

Corresponding author: Antonello D'Andrea

झ antonellodandrea@libero.it

Department of Cardiology, Monaldi Hospital-AORN Ospedali dei Colli, Luigi Vanvitelli University, Corso Vittorio Emanuele $121^{\circ}, 80121$ - Naples, Italy.

Tel: 390817064242

Citation: Liccardo B, Formisano T, D’Andrea A, Giordano M, Martone F, et al. (2018) Diagnosis, Management and Treatment of Septic Shock from Early Diagnosis to Infection Focus Control. Med Case Rep Vol.4 No.1: 56.

SIRS is characterized by presence of two or more of following criteria [4]:

- Temperature $>38^{\circ} \mathrm{C}$ or $<36^{\circ} \mathrm{C}$

- Heart rate $>90 / \mathrm{min}$

- Respiratory rate $>20 / \mathrm{min}$ or $\mathrm{PaCO}_{2}<32 \mathrm{mmHg}(4.3 \mathrm{kPa}$ )

- White blood cell count $>12.000 / \mathrm{mm}^{3}$ or $<4000 / \mathrm{mm}^{3}$ or $>10 \%$ immature bands

These criteria to identify sepsis were unhelpful, because changes in white blood cell count, temperature, and heart rate reflect the physiologic response to infection and/or danger insult, and they don't necessarily indicate a dysregulated, life-threatening response, but they had a poor specificity [5]. 
For this reason, the Third International Consensus Definitions for sepsis and septic shock, published on February 2016, has established a new definition of sepsis underlining the role of organ dysfunction in sepsis rather than the systemic inflammatory response. In fact, sepsis is now defined as "A life-threating organ dysfunction caused by dysregulated host response to infection"; for all this reasons the term severe sepsis is now unnecessary.

Acute organ dysfunction most commonly affects respiratory and cardiovascular systems, but often also brain, kidneys and liver are involved. To help physicians to make diagnosis, the Consensus has introduced a new score to identify promptly the sepsis-related organ damage: the Sequential Organ Failure Assessment Score (SOFA score) (Table 1).

The baseline SOFA score can be assumed to be zero in patients who don't known have pre-existing organ dysfunction. For patients with comorbidities determining organ dysfunction can be useful calculate a baseline SOFA score before the infection, also retrospectively, to evaluate an eventual change of this score during an infection. Patients with a SOFA score of 2 or more had a mortality risk of $10 \%$ in a general hospital population with presumed infection. A SOFA increase $\geq 2$ points indicates the development of organ dysfunction induced by infection.

The calculation of SOFA score need laboratory tests, and it cannot be done promptly. For this reason, it has been introduced a simple bed-side score, called quick-SOFA (qSOFA), characterized by three clinical variables [6]:

- Respiratory rate $\geq 22 / \mathrm{min}$;

- Altered mental status;

- Systolic blood pressure $(\mathrm{SBP}) \leq 100 \mathrm{mmHg}$.

The score is considered positive if there are 2 of 3 criteria.
Although qSOFA is less robust than SOFA score, it does not require laboratory tests and can be assessed quickly and repeatedly. Positive qSOFA criteria should also prompt consideration of possible infection in patients not previously recognized as infected [7].

If not recognized and treated promptly, sepsis can determine cardiovascular dysfunction with consequent septic shock.

Septic shock is defined by the presence of these two criteria [7]:

- Persisting hypotension requiring vasopressors to maintain mean arterial pressure (MAP) $\geq 65 \mathrm{mmHg}$

- Serum lactate level $>2 \mathrm{mmol} / \mathrm{L}(18 \mathrm{mg} / \mathrm{dL}$ ) despite adequate volume resuscitation.

Septic shock is a distributive shock characterized by an extreme peripheral vasodilatation with normal or increased cardiac output and central venous oxygen saturation $\left(\mathrm{ScvO}_{2}\right)$.

Septic shock presents two phases [8]:

- An early warm phase, characterized by normal or increased cardiac output and central venous saturation, low peripheral vascular resistance, wide pulse pressure, bounding pulse, brisk capillary refill (<3 sec.);

- A late cold phase, characterized by low cardiac output and central venous saturation, high peripheral vascular resistance, narrow pulse pressure, weak pulse, delayed capillary refill ( $>5$ $\mathrm{sec})$.

According to these new definitions and scores introduced about sepsis and septic shock, the Task Force recommends a simple and systematic approach to a patient with suspected infection (Figure 1), to obtain an immediate diagnosis and treatment [7].

Table 1 Sequential Organ Failure Assessment Score (SOFA Score).

\begin{tabular}{|c|c|c|c|c|c|}
\hline Variables & \multicolumn{5}{|c|}{ Score } \\
\hline Organ & 0 & 1 & 2 & 3 & 4 \\
\hline \multicolumn{6}{|c|}{ Lung } \\
\hline $\mathrm{PaO}_{2} / \mathrm{FIO}_{2}, \mathrm{mmHg}$ & $\geq 400$ & $<400$ & $<300$ & $\begin{array}{c}<200 \text { with respiratory } \\
\text { support }\end{array}$ & $\begin{array}{c}<100 \text { with respiratory } \\
\text { support }\end{array}$ \\
\hline \multicolumn{6}{|l|}{ Coagulation } \\
\hline Platelets, $\times 10^{3} / \mu \mathrm{L}$ & $\geq 150$ & $<150$ & $<100$ & $<50$ & $<20$ \\
\hline \multicolumn{6}{|c|}{ Liver } \\
\hline Bilirubin, $\mathrm{mg} / \mathrm{dL}$ & $<1.2$ & $1.2-1.9$ & $2.0-5.9$ & $6.0-11.9$ & $>12.0$ \\
\hline \multicolumn{6}{|c|}{ Heart } \\
\hline MAP & $\mathrm{MAP} \geq 70 \mathrm{mmHg}$ & MAP $<70 \mathrm{mmHg}$ & $\begin{array}{l}\text { Dopamine }<5 \text { or } \\
\text { dobutamine (any } \\
\text { dose) })^{1}\end{array}$ & $\begin{array}{l}\text { Dopamine } 5.1-15 \text { or } \\
\text { epinephrine } \leq 0.1 \text { or } \\
\text { norepinephrine } \leq 0.1^{1}\end{array}$ & $\begin{array}{l}\text { Dopamine }>15 \text { or } \\
\text { epinephrine }>0.1 \text { or } \\
\text { norepinephrine }>0.1^{1}\end{array}$ \\
\hline \multicolumn{6}{|c|}{ Brain } \\
\hline Glasgow Coma Scale score ${ }^{2}$ & 15 & $13-14$ & $10-12$ & $6-9$ & $<6$ \\
\hline \multicolumn{6}{|l|}{ Kidney } \\
\hline Creatinine, mg/dL & $<1.2$ & $1.2-1.9$ & $2.0-3.4$ & $3.5-4.9$ & $>5.0$ \\
\hline Urine output, $\mathrm{m} / \mathrm{dL}$ & & & & $<500$ & $<200$ \\
\hline \multicolumn{6}{|c|}{$\begin{array}{l}\text { Adapted from Consensus Definitions for Sepsis and Septic Shock. } \\
\mathrm{FIO} \text { fraction of inspired oxygen; } \mathrm{MAP}, \mathrm{mean} \text { arterial pressure; } \mathrm{PaO}_{2} \text { partial pressure of oxygen } \\
{ }^{1} \text { Catecholamine doses are given as } \mu \mathrm{g} / \mathrm{kg} / \mathrm{min} \text { for at least } 1 \text { hour } \\
{ }^{2} \text { Glasgow Coma Scale scores range from } 3-15 \text {; higher score indicates better neurological function }\end{array}$} \\
\hline
\end{tabular}




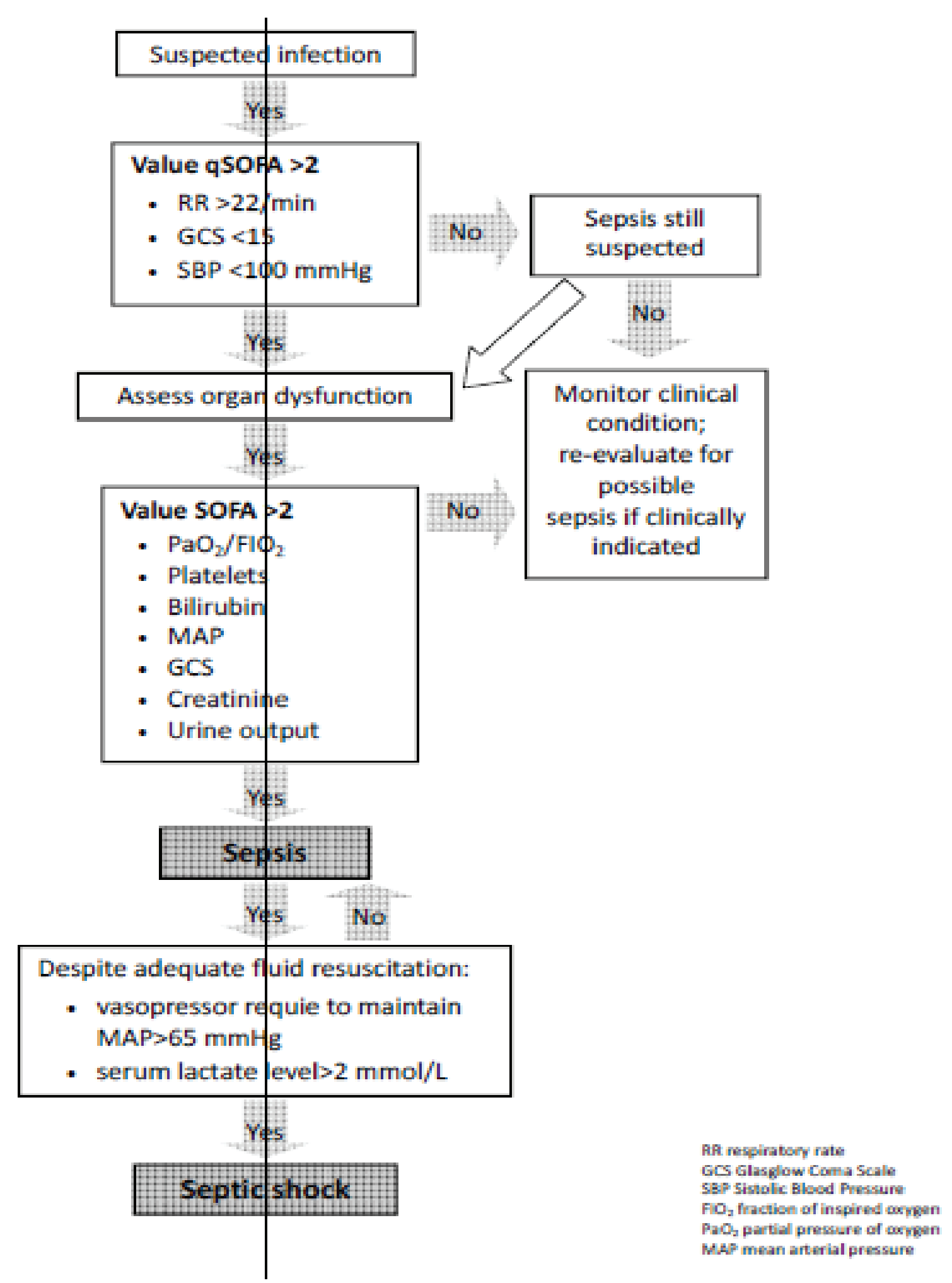

Figure 1 A systematic approach to a patient with suspected infection to obtain an immediate diagnosis and treatment [7].

\section{Treatment}

The management of septic shock regards two aspects: the early management and the control of focus of infection. The early management involves the stabilization of airway and breathing and the assessment of perfusion. First line breathing support is represented by oxygen supplement. Intubation and mechanical ventilation may be required in patient with increased work of 
breathing or for airway protection because encephalopathy and a depressed level of consciousness frequently complicate sepsis. Chest radiographs, lung echography and arterial blood gas analysis should be obtained following initial stabilization to monitoring patient and to diagnose acute respiratory distress syndrome (ARDS), which frequently complicates sepsis [9]. After breathing stabilization, the second step is to assess perfusion.

A compromised perfusion is characterized by Singer et al. and Vincent et al. $[7,8]$ :

- Hypotension (SBP $<90 \mathrm{mmHg}$, mean arterial pressure (MAP) $<70 \mathrm{mmHg}$, decreased SBP >40 mmHg);

- Tachycardia;

- Hypoperfusion (urine output $<0.5 \mathrm{ml} / \mathrm{kg} / \mathrm{h}$, altered mental state which includes delirium, obtundation, disorientation, and confusion);

- Cutaneous alterations (flushed, and hot skin in early warm phase, and cyanotic, and cold skin in late cold phase);

- Hyperlactatemia (>2,0 mmol/l or $>18 \mathrm{mg} / \mathrm{dl}$ ) that express an abnormal cellular oxygen metabolism.

The first line therapy to restore circulation uses fluids to correct intravascular hypovolemia and vasopressors to correct peripheral vasodilatation.

In fluids resuscitation it's important the type of fluids, the volume infused, and the timing of infusion. Randomized clinical trials have demonstrated that normal saline solutions (or other crystalloids as Ringer's lactate and Ringer's acetate) are better and safer than colloids which are associated with increased mortality and acute kidney failure, above all the solution hydroxyethyl starch (HES) $[10,11]$.

A valid alternative to saline solution is represented by albumin. In SAFE trial there were no significative differences of outcomes between the groups of ill critically patients treated with $0.9 \%$ sodium chloride (normal saline) and the group treated with albumin [12]. For these reasons, isotonic, balanced salt solution are a pragmatic initial resuscitation fluid for the majority of acutely ill patients, while albumin can be considered as alternative approach during the early resuscitation of patients with septic shock. HES is not indicated in patients with sepsis or at risk for acute kidney injury [13].

Fluids should be rapidly infused as intravenous boluses (1000 $\mathrm{mL}$ of crystalloids or 300 to $500 \mathrm{~mL}$ of colloids over the course of 30 minutes) until the restoration of an appropriate tissue perfusion (maximum volume 3-5 I) [14-17]. Moreover fluid can also administer by passive leg raise that can predict fluid responsiveness, and can reduce excessive fluid administration and its consequences.

During fluid therapy it should be evaluated not only the tissue perfusion but also the eventual development of pulmonary oedema (because septic patients frequently develop ARDS). For this reason a lung echographic monitoring is helpful to evidence the presence of lung congestion (represented by echographic $B$-profile) during fluid infusion. The presence of lung congestion is an indication to stop fluids and to administer furosemide to avoid the development of a pulmonary oedema $[18,19]$.

When despite ad adequate fluid therapy the hypotension and tissue hypoperfusion persist, vasopressors are indicated as next step of early resuscitation management. First line vasopressor is norepinephrine $(0.01-3 \mathrm{mcg} / \mathrm{kg} / \mathrm{min}$ in dextrose $5 \%$ water). Norepinephrine is a potent alfa-1 adrenergic receptor agonist with modest beta agonist activity which renders it a powerful vasoconstrictor with less potent direct inotropic properties $[14,20]$. Dopamine can be used as an alternative vasopressor agent to norepinephrine only in highly selected patients (patients with low risk of tachyarrhythmias and absolute or relative bradycardia) [14].

Phenylephrine $(0.01-0,1 \mathrm{mcg} / \mathrm{kg} / \mathrm{min}$ in dextrose $5 \%$ water) is useful in patients with tachycardia or arrhythmias because of its pure alfa adrenergic activity and virtually no affinity for beta adrenergic receptors [21]. Vasopressin at the dosage of 0.03 units/minute in dextrose $5 \%$ water can be added to norepinephrine with intent of either raising MAP beyond 70 $\mathrm{mmHg}$ or decreasing vasopressors dosage. Low dose vasopressin is not recommended as the single initial vasopressor for treatment of sepsis-induced hypotension [22]. Higher doses of vasopressin are not recommended because increase the risk of collateral effects as low intestinal mucosal perfusion, high bilirubin and serum transaminases, and decreased platelet counts [23]. When septic shock evolves towards the cold phase, it is necessary to treat cardiac dysfunction (expressed by reduced cardiac output) using an inotrope drug. Dobutamine is the first choice drug (2-20 $\mathrm{mcg} / \mathrm{kg} / \mathrm{min}$ either in $0,9 \%$ chloride solution or in dextrose $5 \%$ water) for treatment of sepsis-induced myocardial dysfunction [14]. Dobutamine is a potent inotrope with a low chronotropic activity. Its effect on vascular smooth muscle is related to dosage. Lower doses $(<5 \mathrm{mcg} / \mathrm{kg} / \mathrm{min}$ ) determine mild vasodilatation with consequent decreased blood pressure, whereas doses up to $15 \mathrm{mcg} / \mathrm{kg} / \mathrm{min}$ increase cardiac contractility without affecting peripheral resistant [24]. Red blood transfusion is indicated only in patients with an haemoglobin level $<7.0 \mathrm{~g} / \mathrm{dL}$. It's reasonable to obtain a haematocrit about 30\% (haemoglobin level $10 \mathrm{~g} / \mathrm{dL}$ ).

The early resuscitation goals are:

- $M A P \geq 65 \mathrm{mmHg}$;

- Urine output $\geq 0.5 \mathrm{~mL} / \mathrm{kg} / \mathrm{h}$

- Central Venous Pressure (CVP) 8-12 mmHg (inferior vena cava $>15 \mathrm{~mm}$ with an inspiratory collapse $>50 \%$ ) if a central venous access is obtained;

- $\mathrm{ScvO}_{2}>70 \%$.

It is useful monitoring the lactate clearance. It has been demonstrated that a reduction of $10 \%$ of lactate levels in 6 hours correlates with a better prognosis in septic shock patients [25]. Therapeutic targets exposed should be achieved into 6 hours from the onset of hypotension.

The other aspect of management of septic shock is represented by identification and control of septic focus. Accurate anamnesis and physical examination are useful to address physicians to 
identify infective site and to choice an appropriate empirical antimicrobial therapy. Antibiotics should be administered promptly in sepsis, within the first hour ("golden hour") after the onset of hypotension [26,27].

It is necessary to obtain cultures of urine, expectorate, and blood. Cultures should be obtained before starting antimicrobial therapy, within maximum the first 45 minutes. At least two sets of blood cultures (both aerobic and anaerobic bottles) must have be obtained before antimicrobial therapy with at least one obtained percutaneously, and one through each vascular access device, unless the device is recently ( $<48$ hours) inserted. Use of the 1,3 beta-D-glucan assay, mannan and anti-mannan antibody assays can be useful to detect an invasive candidiasis in differential diagnosis of cause of infection. The samples of cultures should not delay the empirical antimicrobial therapy administration over the first hour [14].

The antibiotic empirical treatment should be a broad spectrum therapy against both Gram-positive and Gram-negative bacteria, based on the use of at least two antibiotics with synergic action's mechanism (Table 2). There is growing recognition that MRSA is a cause of sepsis not only in hospitalized patients, but also in community dwelling individuals without recent hospitalization, and for this reason antibiotic choice should be always cover MRSA [28].

Vancomycin is the first line antibiotic therapy in septic patients thanks to its efficacy against MRSA. It should be infused at

Table 2 Vancomicina dose scheme adjustment per kidney failure.

\begin{tabular}{|c|c|}
$\begin{array}{c}\text { Maintaining dose } \\
\text { Creatinine clearance }(\mathrm{mL} / \mathrm{min} \text { per } \\
\left.1.73 \mathrm{~m}^{2}\right)\end{array}$ & Vancomycin dose \\
\hline$>90$ & $15-20 \mathrm{mg} / \mathrm{kg}$ per $12 \mathrm{~h}$ \\
\hline $60-89$ & $20-30$ per $24 \mathrm{~h}$ \\
\hline $45-59$ & $15-20$ per $24 \mathrm{~h}$ \\
\hline $30-44$ & $10-15$ per $24 \mathrm{~h}$ \\
\hline $15-29$ & $7-10$ per $24 \mathrm{~h}$ \\
\hline$<15$ & 10 per $48 \mathrm{~h}$ \\
\hline
\end{tabular}

Table 3 Most important antibiotics dosages using in patients without comorbidities.

\begin{tabular}{|c|c|}
\hline Antibiotics & Dosage \\
\hline Amoxicillin/Clavulanic acid & $2.2 \mathrm{~g} \times 3 /$ die \\
\hline Ampicillin/Sulbactam & $3 \mathrm{~g} \times 3 /$ die \\
\hline Ceftriaxone & $2 \mathrm{~g} / \mathrm{die}$ \\
\hline Cefotaxime & $1 \mathrm{~g} \times 3 /$ die \\
\hline Ceftazidime & $1 \mathrm{~g} \times 3 /$ die \\
\hline Cefepime & $2 \mathrm{~g} \times 2 /$ die \\
\hline Piperacillin/Tazobactam & $4.5 \mathrm{~g} \times 3 /$ die \\
\hline Levofloxacin & $500 \mathrm{mg} \times 2 /$ die \\
\hline Ciprofloxacin & $200 \mathrm{mg} \times 2 /$ die \\
\hline Imipenem & $1 \mathrm{~g} \times 3 /$ die \\
\hline Meropenem & $1 \mathrm{~g} \times 3 /$ die \\
\hline Amikacina & $1 \mathrm{~g} / \mathrm{die}$ \\
\hline Clindamicina & $600 \mathrm{mg} \times 3 /$ die \\
\hline Metronidazolo & $500 \mathrm{mg} \times 3 /$ die \\
\hline Teicoplanina & $40 \mathrm{mg} \times 2 /$ die \\
\hline
\end{tabular}

a dose of $15-20 \mathrm{mg} / \mathrm{kg} \times 2 /$ die intravenous (iv) (1 g $\times 2$ /die iv) with a velocity $<15 \mathrm{mg} / \mathrm{min}$. In very critical ill patients it is recommended to start with a loading dose of $25-30 \mathrm{mg} / \mathrm{kg}$, followed by a maintenance dose of $15-20 \mathrm{mg} / \mathrm{kg} \times 2 /$ die iv $(1 \mathrm{~g} x$ $2 /$ die iv). Clearance of vancomycin is almost renal (about $80-90 \%$ of the drug is excreted unchanged in the urine within 24 hours in patients with normal renal function), and its clearance decreases with creatinine clearance $(\mathrm{CrCl})$ in a linear mode. For this reason, vancomycin dose should be adjusted according to creatinine clearance (Table 3). Due to vancomycin intrinsic nephrotoxicity, renal function should be monitored during the treatment. It has been established that a minimum of two or three consecutive documented increases in serum creatinine concentrations (defined as an increase of $0.5 \mathrm{mg} / \mathrm{dl}$ or a $\geq 50 \%$ increase from baseline, or a drop in calculated $\mathrm{CrCl}$ of $50 \%$ from baseline on two consecutive days) could be due to vancomycin, after several days of therapy. There are no data that support the monitoring of vancomycin plasma level to predict its nephrotoxicity, even if a safety range of $15-20 \mathrm{mg} / \mathrm{L}$ has been established. For this reason it is reasonable to obtain a monitoring of vancomycin plasma level only for long term treatment (more than 3 or 5 days) $[29,30]$.

When vancomycin is contraindicated (intolerance to glycopeptide and pregnancy), daptomycin (4 $\mathrm{mg} / \mathrm{kg}$ iv once/die) and linezolid (600 mg x 2/die per os or iv) are good alternative. Daptomycin is not indicating for suspected pulmonary infection, because it is inactivated by the surfactant [31].

Whereas MRSA and Gram-positive infection are covered by vancomycin, a combined therapy is necessary to cover also Gram-negative. If Pseudomonas is an unlikely pathogen, it is recommended to combine vancomycin with one of the following antibiotics:

- Cephalosporin third generation (Ceftriaxone or cefotaxime);

- Cephalosporin fourth generation (Cefepime);

- Betalactam/betalactamase inhibitors (Piperacillin/ tazobactam, ticarcillin/clavulanate);

- Carbapenem (Imipenem or meropenem).

If the infection is probably due to Pseudomonas, it is recommended to add to vancomycin two others antibiotics with different mechanism of action, chosen from the following:

- Anti-pseudomonal cephalosporin (Ceftazidime, cefepime);

- Anti-pseudomonal carbapenem (Imipenem, meropenem);

- Anti-pseudomonal beta-lactam/lactamase inhibitor (Piperacillin-tazobactam, ticarcillin-clavulanate);

- Fluoroquinolone anti-pseudomonal activity (Ciprofloxacin);

- Aminoglycoside (gentamicin, amikacin); monobactam (Aztreonam).

It is reasonable suspect a fungal infection (Candida spp.), in the following conditions:

- Surgery;

- Parenteral nutrition; 
- Prolonged antimicrobial treatment,

- Severe sepsis;

- Multisite colonization with Candida spp.

Empiric antifungal treatment, mostly with fluconazole, was not associated with a decreased risk of mortality or occurrence of invasive candidiasis. Thus, the routine administration of empirical antifungal therapy should be considered only in neutropenic critically ill patients [32]. Antiviral therapy must be initiated as early as possible in patients with severe sepsis or septic shock of viral origin. Empiric antibiotic therapy should not during for more than 3-5 days. When the blood cultures results are available, it is recommended to start a more appropriate single therapy based on isolated bacteria susceptibilities. Duration of therapy is typically 7-10 days. Longer courses may be considered in patients who have a slow clinical response, undrainable foci of infection, bacteraemia with S. Aureus, some fungal, and viral infections, or immunologic deficiencies, including neutropenia. Blood procalcitonin and reactive $C$ protein (RCP) levels can be evaluated to guide physicians in the prosecution or discontinuation of therapy [14].

\section{Discussion}

The use of corticosteroids in sepsis and septic shock has been discussed for a long time. The potential benefit of steroids therapy is related to its role as inflammatory response regulator and to its hormonal effects to restore cardiovascular homeostasis. Steroids improve hemodynamic status of septic patients because they determine hydric retention, direct vasoconstriction, and a better response to catecholamine [33].

Recent international guidelines on sepsis and septic shock recommend the use of hydrocortisone (200 mg per day) only in patients with a septic shock in whom the hypotension (systolic blood pressure $<90 \mathrm{mmHg}$ ) persists for more than one hour despite adequate fluid resuscitation and vasopressor administration. The hydrocortisone use in this scenario is beneficial only if it is administered within the first eight hours [14].

Response to ACTH testing (Adreno Cortico Tropic Hormone) should not be used to select patients for corticosteroid therapy. Corticosteroids should be administered for 5-7 days. It is recommended a progressive dose reduction until to stop the steroid therapy. Fludrocortisone should not be added

\section{References}

1 Finfer SF (2013) Severe sepsis and septic shock. N Engl J Med 369: 9.

2 Opal SM, Garber GE, LaRosa SP, Maki DG, Freebairn RC, et al. (2003) Systemic host responses in severe sepsis analysed by causative microorganism and treatment effects of drotrecogin alfa (activated). Clin Infect Dis 37: 50-58.

3 Fridkin SK, Hageman JC, Morrison M (2005) Methicillin-resistant Staphylococcus aureus disease in three communities. N Engl J Med 352: 1436.

4 Bone RC, Balk RA, Cerra FB (1992) American College of Chest Physicians/Society of Critical Care Medicine Consensus Conference: to hydrocortisone therapy because it can worse splanchnic perfusion [34].

The management of septic patient regards also others aspects:

- Nutritional support, both enteral and intravenous support;

- Venous thromboembolism prophylaxis;

- Intensive insulin therapy (glycaemia target $140-180 \mathrm{mg} / \mathrm{dl}$ );

- Anti-pyretics therapy.

Recent data are investigating the role of fast-acting beta-1 blocker (esmolol) in septic patients. The benefit of esmolol consist of an improvement of stroke volume (and tissue perfusion) through a reduction of heart rates and so an improvement of diastolic filling [35].

A randomized controlled trial conducted by Morelli et al. studied the role of esmolol in 77 patients with septic shock requiring norepinephrine to maintain a MAP $>65 \mathrm{mmHg}$ despite appropriate volume resuscitation and a heart rate of $95 / \mathrm{min}$ or higher. All patients included in the study had a preserved cardiac systolic function (cardiac index $\geq 2.2 \mathrm{~L} / \mathrm{min} / \mathrm{m}^{2}$ in the presence of a pulmonary arterial occlusion pressure $>18 \mathrm{mmHg}$ ). After 24 hours of hemodynamic optimization, the esmolol infusion commenced at $25 \mathrm{mg} / \mathrm{h}$ and progressively increased the rate at 20 minutes intervals, until to obtain a heart rate between 80 $95 \mathrm{bpm}$. For patients in septic shock, the use of esmolol versus standard care was associated with reduction in heart rates, without increased adverse events. The observed improvement in mortality and other secondary outcomes (stroke volume index, arterial lactatemia, vasopressor and fluids requirement) warrants further investigations [36].

\section{Conclusion}

Sepsis and septic shock is still clinical syndrome with a worse prognosis. A rapid and clear approach is needful for a correct diagnosis. Quick SOFA, SOFA and the new definition of septic shock help to identify quickly patients with sepsis and septic shock and to start the appropriate treatment. Early resuscitation management consists of fluid administration and vasopressor therapy. Infective focus control requires an immediate broad spectrum empirical antibiotic therapy, preceded by the obtaining of cultures, even if they do not delay the starting of antibiotics. All these measurements should be set in the first hour after the onset of hypotension, in the so called "golden hour" and optimized in the first six hours.

definitions for sepsis and organ failure and guidelines for the use of innovative therapies in sepsis. Crit Care Med 20: 864-874.

5 Churpek MM, Zadravecz FJ, Winslow C, Howell MD, Edelson DP (2015) Incidence and prognostic value of the systemic inflammatory response syndrome and organ dysfunctions in ward patients. Am J Respir Crit Care Med 192: 958-964.

6 Freund $\mathrm{Y}$, Lemachatti N, Krastinova E, Van Laer M, Claessens YE, et al. (2017) Prognostic accuracy of sepsis-3 criteria for in-hospital mortality among patients with suspected infection presenting to the Emergency Department. JAMA 317: 301-308.

7 Singer M, Deutschman CS, Seymour CW, Shankar-Hari M, Annane D, et al. (2016) The Third International Consensus Definitions for Sepsis and Septic Shock (Sepsis-3). JAMA 315: 801-810. 
8 Vincent JL, Backer DD (2013) Circulatory shock. N Engl J Med 369: 1726-1734.

9 Sessler CN, Perry JC, Varney KL (2004) Management of severe sepsis and septic shock. Curr Opin Crit Care 10: 354.

10 Perner A (2012) Starch for severe sepsis/septic shock trial (6S).

11 Brunkhorst FM, Engel C, Bloos F (2008) Intensive insulin therapy and pentastarch resuscitation in severe sepsis. N Engl J Med 358: 125.

12 Finfer S, Bellomo R, Boyce N (2004) A comparison of albumin and saline for fluide resuscitation in the ICU. NEJM 350: 2247.

13 Myburgh JA (2013) Resuscitation fluids. NEJM 369: 13.

14 Dellinger RP, Levy MM, Rhodes A (2013) Surviving sepsis campaign: International Guidelines for management of severe sepsis and septic shock 2012. Crit Care Med 41: 580.

15 Perel A (2008) Bench-to-bedside review: The initial hemodynamic resuscitation of the septic patient according to Surviving Sepsis Campaign guidelines - Does one size fit all?. Critical Care 12: 223.

16 Byrne L, Van Haren F (2017) Fluid resuscitation in human sepsis: Time to rewrite history? Ann Intensive Care 7: 4.

17 Rameau A, De With E, Boerma EC (2017) Passive leg raise testing effectively reduces fluid administration in septic shock after correction of non-compliance to test results. Ann Intensive Care 7: 2.

18 Gargani L (2011) Lung ultrasound: A new tool for the cardiologist. Cardiovasc Ultra 9: 6

19 Liccardo B, Martone F, Trambaiolo P, Severino S, Cibinel GA, et al. (2016) Incremental value of thoracic ultrasound in intensive care units: Indications, uses and applications. World J Radiol 8: 460-471

20 Reinhart K, Bloos F, Spies C (1995) Vasoactive drug therapy in sepsis. Springer Verlag, Berlin, Germany, 207.

21 Overgaard CB, Dzavik V (2008) Inotropes and vasopressors. Circulation.

22 International Guidelines for Management of Severe Sepsis and Septic Shock; 2013 Society of Critical Care Medicine, European Society of Intensive Care Medicine.

23 Russell JA (2011) Bench-to-bedside review: Vasopressin in the management of septic shock. Russell Critical Care 15: 226.

24 Ruffolo RR (1987) The pharmacology of dobutamine. Am J Med Sci 294: 244-248.
25 Nguyen HB (2004) Early lactate clearance is associated with improved outcome in severe sepsis and septic shock. Crit Care Med.

26 Gaieski DF, Mikkelsen ME, Band RA, Pines JM, Massone R (2010) Impact of time to antibiotics on survival in patients with severe sepsis or septic shock in whom early goal-directed therapy was initiated in the emergency department. Crit Care Med 38: 1045-1053.

27 Kumar A, Roberts D, Wood KE, Light B, Parrillo JE, et al. (2006) Duration of hypotension before initiation of effective antimicrobial therapy is the critical determinant of survival in human septic shock. Crit Care Med 34: 1589-1596.

28 Fridkin SK, Hageman JC, Morrison M, Sanza LT, Como-Sabetti K, et al. (2005) Methicillin-resistant Staphylococcus aureus disease in three communities. N Engl J Med 352: 1436.

29 Rybak M, Lomaestro B, Rotschafer JC, Moellering R, Craig W, et al. (2009) Therapeutic monitoring of vancomycin in adult patients: a consensus review of the American Society of Health-System Pharmacists, the Infectious Diseases Society of America, and the Society of Infectious Disease Pharmacists. Am J Health-Syst Pharm 66: 82-98.

30 Vandecasteele SJ, De Vriese AS (2010) Recent changes in vancomycin use in renal failure. Kidney International 77: 760-764.

31 Mangoni DE, Carbonara S, lacobello C, Tripodi MF, Carretta A, et al. (2011) Management of infections from cardiac implantable electronic devices: Recommendations from a study panel. Infez Med 19: 207-223.

32 Bailly S, Bouadma L, Azoulay E (2015) Failure of empirical systemic antifungal therapy in mechanically ventilated critically ill patients. Am J Respir Crit Care Med.

33 Djillali A (2011) Corticosteroids for severe sepsis: An evidence-based guide for physicians. Ann Intensive Care 1: 7.

34 Kaufman DA, Mancebo P (2016) Corticosteroid therapy in septic shock. Up To Date.

35 Ince C (2015) To beta block or not to beta block; That is the question? Critical Care 19: 339.

36 Morelli A, Ertmer C, Westphal M, Rehberg S, Kampmeier T, et al. (2013) Effect of heart rate control with esmolol on hemodynamic and clinical outcomes in patients with septic shock: A randomized clinical trial. JAMA 310: 1683-1691. 